\title{
Surface Roughness Modeling with Edge Radius and End Milling Parameters on Al 7075 Alloy Using Taguchi and Regression Methods
}

\author{
M. Numan Durakbaşa ${ }^{1}$, Anıl Akdoğan ${ }^{2}$, A. Serdar Vanlı ${ }^{2}$, Aslı Günay ${ }^{2}$ \\ ${ }^{1}$ Vienna University of Technology, Institute for Production Engineering and LaserTechnology, Department for Interchangeable \\ Manufacturing and Industrial Metrology, 1040 Vienna, Austria \\ ${ }^{2}$ Yildiz Technical University, Faculty of Mechanical Engineering, Department of Mechanical Engineering, 34349, Istanbul, Turkey
}

\begin{abstract}
Tool geometry and edge radius are not only crucial for workpiece surface characteristics determination but they also have direct impacts on tool lifetime. They are created in manufacturing and deformations occur in machining processes. With this regard, precise determination of the geometry is of vital importance. This study focused on process parameters like cutting speed, feed rate, depth of cut, tool geometry, and different coatings, to indicate the effects on surface roughness of the machined product on the basis of two and three-dimensional precise measurements. This paper studies the optimization of process parameters and different coating materials with combined different tool radii to obtain the maximum surface quality for the end milling process of Al 7075 alloy by Taguchi and Regression methods. The results revealed optimum process parameters with the proper coating type. The calculated mathematical model predicts average surface roughness value against edge radius wear and processing parameters.
\end{abstract}

\section{Section: RESEARCH PAPER}

Keywords: Edge radius; surface roughness; precise measurements; optimization

Citation: M. Numan Durakbaşa, Anıl Akdoğan, A. Serdar Vanlı, Aslı Günay, Surface Roughness Modeling with Edge Radius and End Milling Parameters on Al 7075 Alloy Using Taguchi and Regression Methods, Acta IMEKO, vol. 3, no. 4, article 9, December 2014, identifier: IMEKO-ACTA-03 (2014)-04-09

Editor: Paolo Carbone, University of Perugia

Received October $10^{\text {th }}, 2013$; In final form December $26^{\text {th }}, 2013$; Published December 2014

Copyright: (C) 2014 IMEKO. This is an open-access article distributed under the terms of the Creative Commons Attribution 3.0 License, which permits unrestricted use, distribution, and reproduction in any medium, provided the original author and source are credited

Funding: This work was supported by Yildiz Technical University, Scientific Research Projects Coordination Department - Project Number: 2012-06-01-KAP01, Turkey.

Corresponding author: Anıl Akdoğan, e-mail: nomak@yildiz.edu.tr

\section{INTRODUCTION}

Despite of recent developments, causes of cutting tool geometry deformations incurred by usage is still unknown and not possible to estimate precisely yet. Since the costs of cutting tools and their replacements in machining processes influence the total production costs by $3 \%$ and $12 \%$, respectively, accurate measurement of tool geometry is of great importance to delay the tool deformations and to extend tool lifetime period [1]. Quality assurance policies are used by many various companies to provide clients with high qualified products and technical support. Thus, inprocess inspections should include all steps of manufacturing to meet the demands of related quality management system standards [2].
Many different industries set high demands on geometry variation of tools due to the technological developments. These high demands stem from high and ultra-high precision machining of different kinds of materials. For instance, while cutting of brittle materials in a ductile mode using diamond tools, such as ductile cutting of silicon and quartz for wafer fabrication, one of the key conditions for achieving ductile chip formation is to get the right cutting edge radius of the tool to the undeformed chip thickness. It has been shown that the undeformed chip thickness has to be in the order of nanometers and that the tool cutting edge radius has to be smaller than the undeformed chip thickness. Therefore, precise measurement of diamond 
Table 1. Chemical composition of Al 7075 alloy.

\begin{tabular}{rcccccccc}
\hline Material & $\mathrm{Si}$ & $\mathrm{Fe}$ & $\mathrm{Cu}$ & $\mathrm{Mn}$ & $\mathrm{Mg}$ & $\mathrm{Cr}$ & $\mathrm{Zn}$ & $\mathrm{Ti}$ \\
\hline$\%$ & 0.08 & 0.36 & 1.52 & 0.08 & 2.59 & 0.21 & 5.62 & 0.04 \\
\hline
\end{tabular}

cutting tools has become a key issue for ductile mode cutting of brittle materials [3].

As emphasized in the literature, cutting tool tip radius deformations during the machining, according to the wear mechanism, is still poorly understood and cannot be accurately predicted [4]. Determining significant factors which affect the tool tip radius is crucial for the final surface quality and life of the tool. The precise identification of tool geometry is important for the determination of both tool life and machined material surface conditions. Tool geometry identification, including edge radius determination gives not only important information on high precise manufacturing processes, but also explains the wear behavior of the tool. High precision measurement techniques are being used to determine the geometry and especially the edge radius variations of various machining operations tools.

Recently, 7xxx series $\mathrm{Al}$ alloy are being used in different experimental studies. Al 7076-T6 material was used for investigating high-speed milling effects on the final workpiece surface by means of analytical and experimental methods [5]. Al 6061-T6 was used as specimens for micro milling experiments in an experimental study [6]. In another study, Al 5083 blocks (140x70x30 mm) were used to investigate parameter effects on tool lifetime. The Gray based Taguchi method and ANOVA analyses were applied for experimental design and results. This analysis showed that decreasing feed rates increased the tool life [7]. Al 7075T6 alloy specimens were applied in an experimental study for dry cutting high-speed milling operations [8]. To model the cutting forces for face milling operations different kinds of Al 7050 specimens were used in other experimental studies [9-10]. Researchers used Al 6061-series aluminum workpieces in a Taguchi L9 orthogonal experimental array set to obtain significant factors that affect the workpiece surface roughness. ANOVA was used to analyze outputs from an orthogonal array. According to these analyses, a low feed rate and a minimum rake angle create high surface quality at high speed milling operations [11].

The purpose of this study is to determine the geometries of brand new and used end milling tool tips and the final workpiece surface qualities by means of precise measurement techniques and methods. In addition, we aim at determining the optimal process parameters and tool radius by using the Design of Experiment (DoE) methodology. This paper studies the optimization of processing parameters and different coating materials combined with different tool radii to obtain the minimum $\mathrm{R}_{\mathrm{a}}$ (Arithmetical Mean Surface Roughness Parameter) values for the end milling process of Al 7075 alloy by using Taguchi and Regression methods.

Specifically, the tool edge radius was obtained by modern 3D dimensional methods. The geometry has significant effects on surface quality and there are limited numbers of studies on the subject matter. This experimental study aim was determination of high accuracy mathematical model between the $\mathrm{R}_{\mathrm{a}}$ and the processing parameters by using the measurement data. The relationship between the control factors and the response factor "surface roughness" is determined. The results revealed proper coating type and the optimum process parameters. In addition, the calculated mathematical model predicts edge radius changes of the tools against workpiece surface damage.

\section{MATERIALS AND METHODS}

In this study, Al 7075 Alloy workpieces were end milled by using 3 different coated milling tools of 3 different initial edge radii. Each tool has four flutes with a $30^{\circ}$ helix angle and $10 \mathrm{~mm}$ nominal diameter. The selected solid carbide cutting tools for experiments were coated with 3 different coating materials by PVD (Plasma Vapor Deposition) technique.

Aluminum alloys are widely used in aerospace and automotive industries to manufacture products in short processing periods to supply a large number of manufactured products by high-speed machining. The manufacturing of such a significant amount of products requires high productivity with an increased cutting speed and feed rate. Al 7075 alloy blocks were used for each set of experiments. The chemical composition of the processed material is given in Table 1 . The experiments were conducted in two different sets of processing parameters, such that observation of the effects of the harder cutting conditions on tool edge geometry is possible. The experiments were classified into two sets, namely "the first milling operations $\left(1^{\text {st }}\right)$ " and "the second milling operations $\left(2^{\text {nd }}\right)$. . Experimental design factors and their levels are given in Table 2. The 27 different $\mathrm{Al}$ alloy blocks had a $50 \times 50$ $\mathrm{mm}$ cross section and a length of $160 \mathrm{~mm}$. The method presented in this study is an experimental design process called the Taguchi Design by which the inherent variability of materials and manufacturing processes have been taken into account at the design stage. In the Taguchi design procedure, the parameter design stage has been widely used for optimization of manufacturing processes $[12,13]$. The vital aim of this experimental work is to determine the optimal cutting conditions that yield the minimum $\mathrm{R}_{\mathrm{a}}$ value. In a significant number of studies, only three common process parameters, i.e. feed rate, cutting speed and depth of cut were experimented [14-17]. Manufacturers and customers are expected to test functional geometry and wear characteristics of tools to ensure that only functionally capable tools are used in the production process. For these purposes, the initial geometrical and surface characteristics of the brand new tools are examined in both 2D and 3D measurements. Edge radii of the brand new and mill-processed tools are measured by a Zoller Venturion 450 - 3D laser scanner, Germany. Images were captured by a Keyence - optical microscope, US, and a Schut - stereo microscope, The Netherlands. The milling 
Table 2. Experimental control factors and their levels.

\begin{tabular}{|c|c|c|c|c|c|c|}
\hline \multirow{2}{*}{$\begin{array}{l}\text { Control } \\
\text { Factors }\end{array}$} & \multicolumn{3}{|c|}{ 1st Milling Operation } & \multicolumn{3}{|c|}{ 2nd Milling Operation } \\
\hline & Level 1 & Level 2 & Level 3 & Level 1 & Level 2 & Level 3 \\
\hline $\begin{array}{c}\text { Radius } \\
\text { (mm) }\end{array}$ & 0.5 & 1 & 1.5 & 0.5 & 1 & 1.5 \\
\hline $\begin{array}{l}\text { Coating } \\
\text { Type }\end{array}$ & AlTiN & AITiCN & $\mathrm{ZrN}$ & AlTiN & AITiCN & $\mathrm{ZrN}$ \\
\hline Cutting & & & & & & \\
\hline $\begin{array}{l}\text { Speed } \\
\text { (m/min) }\end{array}$ & 50 & 75 & 100 & 100 & 150 & 200 \\
\hline $\begin{array}{l}\text { Depth of } \\
\text { Cut (mm) }\end{array}$ & 0.50 & 0.75 & 1.00 & 0.50 & 0.75 & 1.00 \\
\hline $\begin{array}{l}\text { Feed Rate } \\
\text { (mm/tooth) }\end{array}$ & 0.05 & 0.10 & 0.15 & 0.10 & 0.20 & 0.30 \\
\hline
\end{tabular}

operations were performed on a vertical CNC machining center, Mori Seiki, MillTap 700, Japan. A DIN 6499 ER type tool holder was used in all the experiments. After performing two sets of milling operations, the surface roughness of the machined products were measured by using a profilometer from Taylor Hobson, UK, at five different locations. Repetitive measurements increase the conformity of the model accuracy.

Deformations from previous conditions are provided in Table 3 as $\Delta r_{\varepsilon 1}$ and $\Delta r_{\varepsilon 2}$ respectively for the $1^{\text {st }}$ and $2^{\text {nd }}$ set of milling operations. Additionally, Table 3 shows the response factors at the end of the $1^{\text {st }}$ and $2^{\text {nd }}$ set of operations as $R_{a}$ measurements, respectively. The arithmetic average of the absolute values of the roughness profile was determined by means of a Gauss filter with 0.8 $\mathrm{mm}$ cut off value and $4 \mathrm{~L}$ access length.

Certainly, tool edge radius stability performance is related with the final surface roughness of the workpiece. Therefore, an experimental design was introduced and all test specimen end milling tool radii were measured before and after machining for obtaining deviations from the initial geometry.

By this approach changes of surface conditions and tool tip geometry were obtained accurately. Figure 1 shows the initial tip geometry figures of the $\mathrm{ZrN}$ coated tools at 1.0 $\mathrm{mm}$ and $1.5 \mathrm{~mm}$ nominal radius measurement operations respectively, with $\times 50$ magnification.

\section{RESULTS AND DISCUSSIONS}

Today's high precise manufacturing technology requires practical solutions to improve surface quality of the machined products. At this point, evaluating cutting performance is an important factor. On the basis of this factor, $R_{a}$ values of the milled products were chosen as response to determine end milling performance of the manufacturing systems.

Process parameters that affect the characteristics of milled products are tool characteristic parameters; tool radius and coating material and the milling parameters such as the cutting speed, the feed rate, and the depth of cut.

The presented results were analyzed in the limits of the selected orthogonal array. The basic quality characteristic for this research is the minimum surface roughness for optimum machining conditions. According to the measurements, the minimum surface roughness was

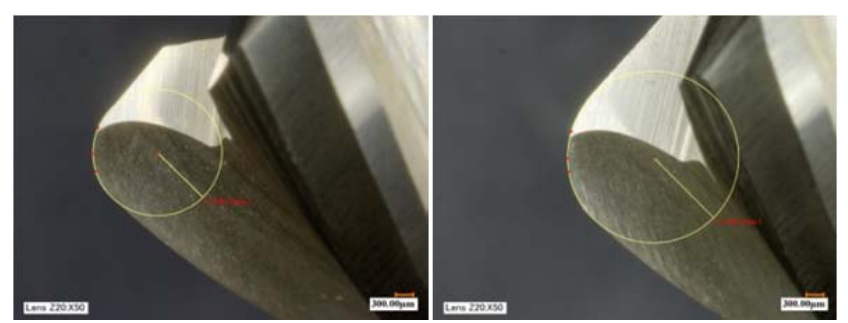

Figure 1. Optical microscope images of $\mathrm{ZrN}$ coated tools of $1.0 \mathrm{~mm}$ and 1.5 $\mathrm{mm}$ nominal radii respectively.

obtained with the third level of radius, the third level of coating, the first level of cutting speed, the second level of depth of cut and the first level of feed rate (Table 4).

The ANOVA statistical analyzing method was used for investigating the most effective process parameters. The results indicated that coating type is the most effective parameter for the surface roughness in accordance with the selected parameters and their levels. The results were provided at the $95 \%$ confidence level.

After determining the optimum levels of the processing parameters and tool edge radius, these levels should be verified. Repetitive machining processes were applied for the verifications. Repetitive surface roughness measurements taken from the work piece are indicated in Table 4. The experimental results are in agreement with the predicted results from the proposed method. The experimental results of the surface roughness were comparable with the predicted values. The mathematical model results and the measured surface roughness values in each experiment were similar. The authors also calculated a similar model in a previous study [18]. In this paper, the presented models predict more accurately the final surface quality by using radius wear effects.

The authors have conducted an ANOVA test for investigating the most effective process parameters for the first step milling operation results. The coating type was determined as the most significant parameter, according to the ANOVA analysis. Analyses showed that the $\mathrm{ZrN}$ type coating provides the best surface quality with a minimum surface roughness of the workpiece. Increasing cutting speed decreases the surface quality, as observed in previous studies [19, 20]. In this experimental work, the minimum cutting speed of $50 \mathrm{~m} / \mathrm{min}$ resulted in a minimum surface roughness. The $\mathrm{S} / \mathrm{N}$ ratio graph shows that at $0.75 \mathrm{~mm}$ depth of cut the best surface roughness were recorded (Figure 2). The depth of cut value has a remarkable impact on the cutting forces. Moreover, it introduces thermal changes during the machining process. The depth of cut effects the chip flow angle, which is crucial for heat dissipation. Thus, the depth of cut is a significant parameter

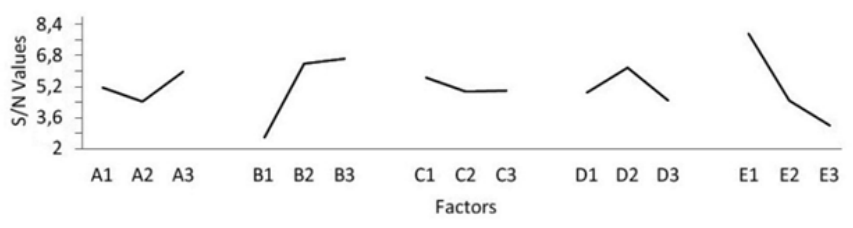

Figure 2. S/N graph for surface roughness for the $1^{\text {st }}$ set operations. 
Table 3. Orthogonal array $L 27$ and the results. $r_{\varepsilon 0}$ :edge radius before milling operation, $r_{\varepsilon 1}$ : edge radius after $1^{\text {st }}$ Milling Operation, $r_{\varepsilon 2}$ : edge radius after $2^{\text {nd }}$ Milling Operation.

\begin{tabular}{|c|c|c|c|c|c|c|c|c|c|}
\hline \multirow[b]{3}{*}{ Run } & \multirow{2}{*}{\multicolumn{5}{|c|}{ Control Factors and Levels }} & \multicolumn{4}{|c|}{$\begin{array}{ll}\text { Response Factors } \\
\end{array}$} \\
\hline & & & & & & \multicolumn{2}{|c|}{$1^{\text {st }}$ Milling Operation } & \multicolumn{2}{|c|}{$2^{\text {nd }}$ Milling Operation } \\
\hline & $\begin{array}{l}\text { Radius } \\
\text { (mm) }\end{array}$ & $\begin{array}{l}\text { Coating } \\
\text { Type }\end{array}$ & $\begin{array}{l}\text { Cutting Speed } \\
V_{c}(\mathrm{~m} / \mathrm{min})\end{array}$ & $\begin{array}{c}\text { Depth of Cut } \\
a_{p}(\mathrm{~mm})\end{array}$ & $\begin{array}{c}\text { Feed Rate } \\
\mathrm{f}_{\mathrm{z}}(\mathrm{mm} / \text { tooth })\end{array}$ & $\begin{array}{c}\operatorname{Mean}\left(1^{\text {st }}\right) \\
R_{a}(\mu \mathrm{m})\end{array}$ & $\begin{array}{c}\Delta r_{\varepsilon 1} \\
\left|r_{\varepsilon 1}-r_{\varepsilon 0}\right| \\
(m m)\end{array}$ & $\begin{array}{c}\text { Mean }\left(2^{\text {nd }}\right) \\
R_{\mathrm{a}}(\mu \mathrm{m})\end{array}$ & $\begin{array}{c}\Delta r_{\varepsilon 2} \\
\left|r_{\varepsilon 2}-r_{\varepsilon 1}\right| \\
(\mathbf{m m})\end{array}$ \\
\hline 1 & 1 & 1 & 1 & 1 & 1 & 0.581 & 0.010 & 1.010 & 0.005 \\
\hline 2 & 1 & 1 & 1 & 1 & 2 & 1.082 & 0.002 & 0.953 & 0.005 \\
\hline 3 & 1 & 1 & 1 & 1 & 3 & 0.617 & 0.005 & 1.290 & 0.010 \\
\hline 4 & 1 & 2 & 2 & 2 & 1 & 0.376 & 0.016 & 0.590 & 0.000 \\
\hline 5 & 1 & 2 & 2 & 2 & 2 & 0.355 & 0.008 & 0.811 & 0.008 \\
\hline 6 & 1 & 2 & 2 & 2 & 3 & 0.639 & 0.006 & 1.321 & 0.007 \\
\hline 7 & 1 & 3 & 3 & 3 & 1 & 0.528 & 0.005 & 2.161 & 0.087 \\
\hline 8 & 1 & 3 & 3 & 3 & 2 & 0.412 & 0.038 & 0.728 & 0.031 \\
\hline 9 & 1 & 3 & 3 & 3 & 3 & 0.648 & 0.004 & 0.922 & 0.005 \\
\hline 10 & 2 & 1 & 2 & 3 & 1 & 0.689 & 0.008 & 1.360 & 0.012 \\
\hline 11 & 2 & 1 & 2 & 3 & 2 & 1.099 & 0.338 & 0.855 & 0.337 \\
\hline 12 & 2 & 1 & 2 & 3 & 3 & 0.992 & 0.010 & 1.350 & 0.009 \\
\hline 13 & 2 & 2 & 3 & 1 & 1 & 0.487 & 0.023 & 0.694 & 0.014 \\
\hline 14 & 2 & 2 & 3 & 1 & 2 & 0.509 & 0.003 & 0.502 & 0.021 \\
\hline 15 & 2 & 2 & 3 & 1 & 3 & 0.684 & 0.000 & 0.679 & 0.003 \\
\hline 16 & 2 & 3 & 1 & 2 & 1 & 0.277 & 0.041 & 0.274 & 0.011 \\
\hline 17 & 2 & 3 & 1 & 2 & 2 & 0.340 & 0.031 & 0.589 & 0.007 \\
\hline 18 & 2 & 3 & 1 & 2 & 3 & 0.839 & 0.021 & 1.054 & 0.009 \\
\hline 19 & 3 & 1 & 3 & 2 & 1 & 0.366 & 0.000 & 0.448 & 0.021 \\
\hline 20 & 3 & 1 & 3 & 2 & 2 & 0.854 & 0.009 & 0.883 & 0.006 \\
\hline 21 & 3 & 1 & 3 & 2 & 3 & 0.758 & 0.001 & 0.895 & 0.002 \\
\hline 22 & 3 & 2 & 1 & 3 & 1 & 0.250 & 0.019 & 0.504 & 0.015 \\
\hline 23 & 3 & 2 & 1 & 3 & 2 & 0.770 & 0.013 & 0.697 & 0.007 \\
\hline 24 & 3 & 2 & 1 & 3 & 3 & 0.472 & 0.001 & 1.025 & 0.013 \\
\hline 25 & 3 & 3 & 2 & 1 & 1 & 0.271 & 0.003 & 0.419 & 0.008 \\
\hline 26 & 3 & 3 & 2 & 1 & 2 & 0.491 & 0.007 & 0.494 & 0.012 \\
\hline 27 & 3 & 3 & 2 & 1 & 3 & 0.697 & 0.002 & 0.743 & 0.004 \\
\hline
\end{tabular}

for the surface quality and the tool lifetime [21-23]. As is indicated, decreasing the feed rate increases the surface quality $[24,25]$. The experiments in this study also confirmed that the minimum feed rate leads to a minimum surface roughness of end milled products.

The regression analysis was used to understand the relationship between the selected parameters and the surface roughness deviations. The calculated mathematic model for the $R_{a}$ is:

$R_{a}=-1.1766+11.7502 \Delta r_{\varepsilon 1}+0.0058 V_{c}+1.1988 a_{p}+4.2456 f_{z}$

Variables were defined as initial edge radius, edge radius after $1^{\text {st }}$ milling operations, cutting speed, depth of cut and feed rate for the regression analysis. As indicated in Eq. (1), the model incorporates the effect of edge radii, cutting speed, depth of cut and feed rate on the surface roughness of the workpiece.

The authors strongly recommend the use of the suggested coating type i.e. $\mathrm{ZrN}$, when using the regression model considering the Taguchi results.

The edge radius change, $\Delta \mathrm{r}_{\varepsilon 1}$, was also determined as an important parameter during the machining process according to the Taguchi method. According to the results, when the edge radius increases, the surface quality improves, related to the depth of the cut values. On the other hand, when the feed rate decreases, the surface quality increases. The feed rate appeared to be the most effective parameter after the coating type for a better surface quality. By the created regression model, $85.53 \%$ of the total variability in the deviation can be explained by Eq. (1).

The $2^{\text {nd }}$ milling operations were conducted using more aggressive processing parameters, doubling $V_{\mathrm{c}}$ and $f_{\mathrm{z}}$. The results of the $2^{\text {nd }}$ Taguchi analysis verified the optimum process parameters in the $1^{\text {st }}$ operation. The $\mathrm{S} / \mathrm{N}$ ratio graph indicates that $50 \mathrm{~m} / \mathrm{min}$ minimum cutting speed, $0.75 \mathrm{~mm}$ depth of cut and $0.05 \mathrm{~mm} /$ tooth minimum feed rate resulted in a minimum surface roughness values (Figure 3). In addition, a TiAlCN type coating was suggested based on these results.

The regression analysis model was run to understand the relationship between the process parameters and the surface roughness for the $2^{\text {nd }}$ milling operation. The calculated mathematical model for the $\mathrm{R}_{\mathrm{a}}$ is indicated in Eq. (2). $88.96 \%$ of the total variability in the deviation can be explained by this model.

$$
R_{a}=-0.2610-4.7204 \Delta r_{\varepsilon 2}+0.0054 V_{c}+0.2505 a_{p}+3.9257 f_{z}
$$

Table 4. Confirmation tests results.

\begin{tabular}{|c|c|c|c|c|c|c|c|}
\hline \multicolumn{4}{|c|}{ Control Factors and Levels } & \multicolumn{4}{|c|}{ Roughness Values $(\mu \mathrm{m})$} \\
\hline Radius (mm) & Cutting Speed ( $\mathrm{m} / \mathrm{min})$ & Depth of Cut (mm) & Feed Rate (mm/tooth) & Exp.1 & Exp. 2 & Exp.3 & Predicted \\
\hline 1.5 & 50 & 0.75 & 0.05 & 0.269 & 0.262 & 0.196 & 0.283 \\
\hline
\end{tabular}




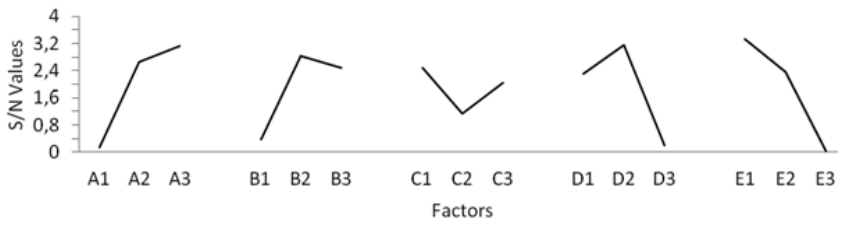

Figure 3. S/N graph for Surface Roughness for the $2^{\text {nd }}$ set operations.

\section{CONCLUSIONS}

This experimental work is about optimizing the processing parameters by using different coating materials which were combined with different tool radii to obtain the minimum $R_{a}$ values for the end milling of Al 7075 alloys. The Taguchi method was used for the experimental design. Tool edge radii and machined surface roughness were measured by means of high precision measurement techniques. Surface roughness values were used as output for the analysis.

Experimental results and the regression models confirmed that the increased wear of edge radii decreased the surface quality of the machined workpiece. According to the proposed optimization method, the optimum process parameters, the minimum cutting speed, the average depth of cut, the minimum feed rate and the maximum edge radius provided the best surface quality for Al 7075 alloy. Besides, according to the regression analysis results, $\mathrm{ZrN}$ coating types for relatively low cutting speeds and TiAlCN coating types for cutting speeds higher than $100 \mathrm{~m} / \mathrm{min}$ gave the best surface roughness performance.

In addition, a relationship between the work piece surface roughness and a cutting tool edge radius were found according to the experimental runs. In conclusion, tool edge radius wear was found to be a crucial parameter, as well as the feed rate, the depth of cut and the cutting speed. This study provides an insight into the relationship between the wear mechanism of the tools and the surface quality of a workpiece, according to the processing parameters.

\section{ACKNOWLEDGEMENT}

This research has been supported by Yildiz Technical University, Scientific Research Projects Coordination Department, Istanbul, Turkey, Project Number: 2012-0601-KAP01. The Authors are thankful to Milmak Metal, İstanbul, and DMG Mori Seiki, İstanbul, Turkey for their support.

\section{REFERENCES}

[1] A.Weckenmann, K Nalkntic, "Precision Measurement of Cutting Tools with two Matched Optical 3D sensors", Manuf. Techn., 52, 443-446, 2003, http://dx.doi.org/10.1016/S0007-8506(07)60621-0.

[2] ISO 9001:2008, "Quality management systems Requirements".

[3] Li X. P., Rahman M., Liu K., Neo. K. S., Chan C. C., "Nano- precision measurement of diamond tool edge radius for wafer fabrication", J. Mater. Process. Techn., 140, 358362, 2003, http://dx.doi.org/10.1016/S0924-0136(03)00757$\mathrm{X}$.
[4] Durazo-Cardenas I., Shpre P., Luo X., Jacklin T.Imprey S. A., Cox A., "3D Characterization of tool wear whilst diamond turning silicon”, Wear, 262, 340- 349, 2007, http://dx.doi.org/10.1016/j.wear.2006.05.022.

[5] Rao B., Shin Y.C., "Analysis on high speed face milling of 7075-T6 Al using carbide and diamond cutters", Int. J. Mach. Tool. Manu., 41, 1763-1781, 2001, http://dx.doi.org/10.1016/S0890-6955(01)00033-5

[6] Chern G.L. ve Chang Y.C., "Using two dimensional vibration cutting for micro milling”, Int. J. Mach. Tool. Manu., 46, 659-666, 2006, http://dx.doi.org/10.1016/j.ijmachtools.2005.07.006.

[7] Kopac J., Krajnik B., "Robust design of flank milling parameters based on grey-Taguchi method", J. Mater. Process. Techn., 191, 400-403,2007. http://dx.doi.org/10.1016/j.jmatprotec.2007.03.051.

[8] Rivero A., Lacelle L.N.L., Penelva M.L., "Tool wear detection in dry high speed milling based upon the analysis of machine internal signals”, Mechatronics, 18, 627-633, 2008 ,

http://dx.doi.org/10.1016/j.mechatronics.2008.06.008.

[9] Dang J. W., Zhang W.H., Yang Y., Wan M., "Cutting force modelling for flat end milling including bottom edge cutting effect”, Int. J. Mach. Tool. Manu., 50, 986-997, 2010, http://dx.doi.org/10.1016/j.ijmachtools.2010.07.004.

[10] Wan M., Lu M.S., Zhang W.H., Yang Y., "A new ternary mechanism model for the prediction of cutting forces in flat end milling”, Int. J. Mach. Tool. Manu., 57, 34-45, 2012, http://dx.doi.org/10.1016/j.ijmachtools.2012.02.003.

[11] Baharudin B.T.H.T., Ibrahim M.R., Ismail N., Leman Z., Ariffin M.K.A., Majid D.L., "Experimental investigation of HSS face milling to Al 6061 using Taguchi method", Procedia Engineerimg, 50, 933-941, 2012. http://dx.doi.org/10.1016/j.proeng.2012.10.101.

[12] Fowlkes Y., Creveling C. M., "Engineering Methods for Robust Product Design, Using Taguchi Methods in Technology and Product Development", Addison-Wisley Publishing Company, 1995, ISBN 0-201-63367-1.

[13] Afazov S.M., Ratchev S.M., Segal J., "Modelling and simulation of micro-milling cutting forces", J. Mater. Process. Techn., 210, 2154-2162, 2010.

http://dx.doi.org/10.1016/j.jmatprotec.2010.07.033.

[14] Adeel H., Suhail N., Ismail S., Wong V. and Abdul Jalil N.A., "Cutting parameters identification using multi adaptive network based Fuzzy inference system: An artificial intelligence approach", Scientific Research and Essays, 6(1), 187-195, 2011.

[15] Ghani J.A., Choudhury I.A., Hassan H.H., "Application of Taguchi method in the optimization of end milling parameters", J. Mater. Process. Techn., 145, 84-92, 2004, http://dx.doi.org/10.1016/S0924-0136(03)00865-3.

[16] Nalbant M., Gökkaya H., Sur G., “Application of Taguchi method in the optimization of cutting parameters for surface roughness in turning", Mater. Design, 28, 13791385, 2007, http://dx.doi.org/10.1016/j.matdes.2006.01.008.

[17] Park S.H., "Robust Design and Analysis for Quality Engineering”, Chapman \& Hall, London, 1996, ISBN 0412-55620-0.

[18] Durakbaşa M. N., Akdoğan, A.,Vanlı A. S., Günay A.,”Tip Radius Effects on Surface Roughness of End Milled Al 7075 Using Taguchi and Regression Methods", 12th IMEKO TC10 Workshop on Technical Diagnostics, ID 0015/p.106, 2013. 
[19] Lin H.M., Liao Y.S., Wei C.C.,"Wear behavior in turning high hardness alloy steel by CBN tool", Wear, 264, 679-684, 2008, http://dx.doi.org/10.1016/j.wear.2007.06.006.

[20] Khidhir B. A., Mohamed B.,"Study of cutting speed on surface roughness and chip formation when machining nickel-based alloy", J. Mech. Sci. Technol.,Vol., 24 (5), 2010.

[21] Chen J.-S., Huang Y.-K, Chen M.-S., "Feed rate optimization and tool profile modification for the highefficiency ball-end milling process”, Int. J. Mach. Tool. Manu., 41, 1763-1781, 2001, http://dx.doi.org/10.1016/j.ijmachtools.2004.11.020.

[22] Buj-Corral I., Vivancos-Calvet J. Domínguez-Fernández A., "Surface topography in ball-end milling processes as a function of feed per tooth and radial depth of cut”, Int. J. Mach. Tool. Manu., 53(1), 151-159, 2012.

http://dx.doi.org/10.1016/j.ijmachtools.2011.10.006

[23] Avishan B., Yazdani S., Jalali Vahid D., "The influence of depth of cut on the machinability of an alloyed austempered ductile iron”, Mat. Sci. Eng., 523, 93-98, 2009. http://dx.doi.org/10.1016/j.msea.2009.05.044.

[24] Agarwal N.,"Surface roughness modeling with machining parameters (speed, feed and depth of cut) in CNC milling", MIT Int. J. Mach. Eng., 2, 55-61, 2012.

[25] Colak O., Kurbanoğlu C., Kayacan M. C., "Milling surface roughness prediction using evolutionary programming methods", Mater. Design, 28, 657-666, 2007, http://dx.doi.org/10.1016/j.matdes.2005.07.004. 